\title{
Rare Intraparotid Localization of Kimura's Disease (A Case Report and Literature Review)
}

Othmane Bouanani*, Alain Habimana, Salma Benazzou, Malik Boulaadas

Department of Maxillofacial Surgery Hospital of Specialities-Rabat Faculty of Medicine And Pharmacy-Rabat Mohamed V University Rabat, Morocco

DOI: $10.36347 /$ sjams.2020.v08i11.022

| Received: 30.03 .2020 | Accepted: 06.04.2020 | Published: 16.11.2020

*Corresponding author: Othmane Bouanani

\section{Abstract}

Introduction: Kimura's disease is a very rare chronic inflammatory pathology of unknown etiology. It is actually an allergic or autoimmune reaction process involving blood vessels, lymphocytes and eosinophils. Observation: We report a case of Kimura disease with cervical localization in a 37-year-old Patient who saw the appearance of a swelling of the right parotid region evolving for 1 year. The patient benefited from a total right parotidectomy with homolateral selective curage and the anatomopathological study of the tumoral piece came back in favor of Kimura's disease. The evolution was good. The regression is one year without recurrence. Discussion: Kimura's disease is characterized clinically by subcutaneous nodules of cervicofacial localization, increased volume of salivary glands and satellite adenopathies. Its diagnosis is histological based on the identification of follicular hyperplasia with eosinophilic polynuclear abscesses. Treatment is surgical most often but in some cases corticotherapy is proposed.

Keywords: kimura's disease, parotid tumor, hypereosinophilia.

Copyright $(\mathcal{C} 2020$ The Author(s): This is an open-access article distributed under the terms of the Creative Commons Attribution 4.0 International License (CC BY-NC 4.0) which permits unrestricted use, distribution, and reproduction in any medium for non-commercial use provided the original author and source are credited.

\section{INTRODUCTION}

Kimura's disease or eosinophilic lymphogranuloma is a very rare condition. This is a chronic inflammatory pathology of unknown etiology. It affects almost exclusively patients from the Far East, but can occur more exceptionally in Caucasian subjects [1]. We report a case of Kimura disease with parotid localization and, through a review of the literature; we recall the main clinical, para-clinical, therapeutic and evolutionary features of this pathology.

\section{ObServation}

This is a 40-year-old patient, who has been consulting for a swelling of the left parotid region, evolving over the last two years, gradually increasing in volume, painful, accompanied by inflammatory episodes with no trismus and facial asymmetry. The clinical examination found a patient in good general condition, apyretic, with normal colored conjunctives. On inspection there was a swelling of the left parotid region with inflammatory signs of the skin (Figure 1,2). At palpation, a swelling of firm consistency, poorly limited, painful, nonflapping, mobile in relation to the superficial and deep planes, measuring about $6 \mathrm{~cm}$ of long axis. The cervical lymph node areas were free. Examination of the oral cavity and oropharynx showed no pyosialie, haeosialie, or swelling of the posterolateral wall of the oropharynx. The general examination was without particularities. A cervico-parotid ultrasound was requested and revealed an enlarged parotid gland with heterogeneous echostructure. A cervico-facial computed tomography showed an enlarged left parotid gland with irregular contours (Figure 3), infiltrating subcutaneous fat tissue outside, without viewing lithiasic image or bone lysis.

CT scan didn't show any cervical lymphadenopathy. Cytoponction revealed polymorphic cell inflammation with the absence of suspicious cells. The biological test found an hypereosinophilia. We decided to perform a total parotidectomy with an extemporaneous exam (Figure 3). Surgical exploration found an inflammatory-looking gland. The extemporaneous examination was in favour of a nonspecific inflammatory reaction made mainly of lymphocytes, with no sign of malignancy. The patient benefited from a total left parotidectomy with no complications. The anatomopathological study concluded with Kimura's disease. 


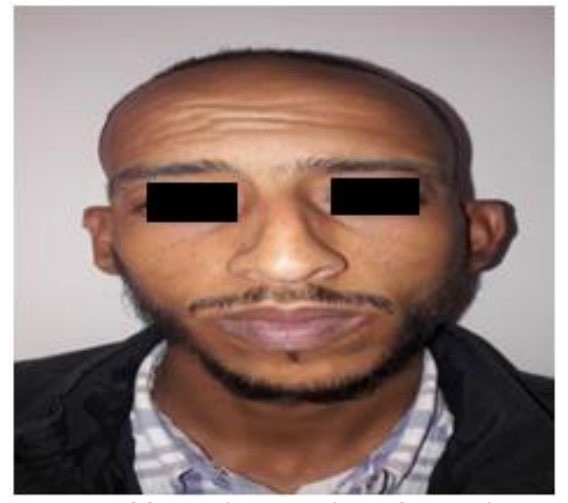

Fig-1: Image of front view showing left parotid swelling

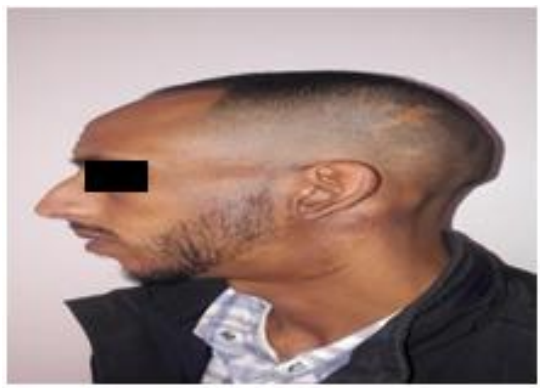

Fig-2:Image of lateral view showing left parotid swelling

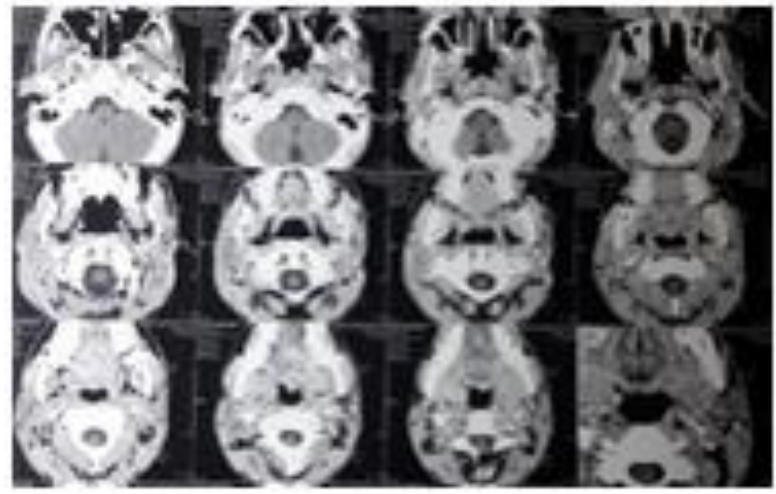

Fig-3: Axial CT scan showing left parotid tumor.

\section{DiSCUSSION}

In 1948, Japanese Kimura was described as the "unusual granuloma associated with hyperplastic changes in lymphoid tissue" of disseminated subcutaneous lesions accompanied by lymphadenopathy and hypereosinophilia of the blood [2]. Kimura's disease mainly affects young men [3, 4], with a sex ratio varying according to studies from 3 to 7 [5]. It affects almost exclusively patients from the Far East, but may occur more exceptionally in Caucasian subjects [1], Kimura's disease can occur at any age, with a peak in frequency in the third and fourth decades [6]. This is a chronic inflammatory pathology of unknown etiology [7]. After considering that Kimura's disease belonged to the tumor group of the vascular endothelium and that it could, as such, be assimilated with angiolymphoid hyperplasia with eosinophilia in Western patients.
Today it is thought that it is actually an allergic or autoimmune reaction process involving blood vessels, lymphocytes and eosinophils. These are fairly poorly limited nodules or subcutaneous closets, of varying size up to that of a palm. Their consistency may be firm or soft. The lesions are not fixed to the deep plane, but adhere to the overlying skin, which is usually of normal color or slightly brownish, exceptionally purplish red. They are multiple in $40 \%$ of cases, and have generally slow growth. The preferred location is cervico-facial as illustrated by our observation (periauricular region, cheeks, lateral sides of the neck and supraclavicular cavities) [9, 10]. Epitrochlean, axillary, inguinal and popliteal localisations are described [11]. Biologically, blood hypereosinophilia is almost found as the case of our patient and there is frequently a hyperimmunoglobulinemia E. Systematically, a proteinuria that will witness nephrotic syndrome should be investigated.

Radiological examinations can be useful in the exploration of Kimura's disease, in order to make its extension as clear as possible. Som and Biller [14] scanned and imaged their patient with Kimura disease affecting the parotid gland and cervical lymph nodes using magnetic resonance imaging. The scanner showed contrast taking of the parotid and the affected homolateral lymph nodes. Since the contrast of the affected areas is similar to that of the carotid artery, vascular participation is thus suggested by the authors. Anatomopathological examination of the lesions shows hyperplasia of lymphoid tissue with florid germinative centres. The differential diagnosis of Kimura's disease is mainly with angiofollicular hyperplasia with eosinophilia. The treatment of Kimura's disease is not codified. Different therapeutic modalities have been proposed. The surgical treatment is indicated in first intention as it was the case of our patient; it consists in carrying out a broad and deep removal in order to avoid recurrences that are frequent [11]. Corticosteroid therapy is by far the most frequently used medical treatment. It is indicated in forms profuse or inaccessible to surgery or systematically in case of renal impairment. It is prescribed at the initial dose of 0.5 to 1 $\mathrm{mg} / \mathrm{kg} / \mathrm{d}$ prednisone with a slow degression over at least 6 months with good efficacy. However relapses are possible when treatment stops. Systemic chemotherapy based on 5-fluoro-uracil and azathioprine was used in combination with general corticotherapy, but its usefulness was not formally demonstrated [10]. Local radiation therapy may be offered in forms refractory to corticosteroids or when surgery is impossible. The total effective dose is between 25 and $30 \mathrm{~Gy}$.

Kimura's disease usually follows a chronic, indolent and benign course, without altering the general condition. Tumour outbreaks can alternate with periods of complete remission. Spontaneous regressions are possible. Recurrences after treatment are classic, 15$40 \%$ [15]. Despite a worrying clinical presentation, with 
involvement of the salivary glands and the presence of lymphadenopathy, often causing the hypothesis of tumors of the salivary glands or lymphoma to be misquoted, no malignant disease has been reported to date. The benign prognosis of the disease must nevertheless be tempered by the possibility of kidney damage sometimes associated.

\section{Conclusion}

Kimura's disease is a rare condition; usually affecting Japanese men aged 20 to 40 . It is characterized by subcutaneous nodules predominating in the head and neck. Its diagnosis is histological. The treatment is not codified but often surgery is used alone as the case of our patient. However, for some cases the indication of general corticotherapy is necessary. The prognosis of the disease remains good.

\section{REFERENCES}

1. Googe PB, Harris NL, Mihm MC., Jr Kimura's disease and angiolymphoid hyperplasia with eosinophilia: two distinct histopathological entities. J Cutan Pathol. 1987 Oct;14(5):263-71.

2. Kimura T, Voschimura S, Ishikawa E. Kimura's disease; on the unusual granulation combinated with hyperplastic changes of lymphatic tissues. Trans Soc Pathol Jpn. 1948;37(1):170-80.

3. Ignatus T, Kung M, Gibson JB, Bannatyne PM. Kimura's disease, a clinico- pathological study of 21 cases and its distinction from angiolymphoid hyperplasia with eosinophilia. Pathology. 1984 Jan;16(1):39-44.

4. Cheney ML, Bhatt S, Googe P, Hibberd PL. Angiolymphoid hyperplasia with eosinophilia: evaluation of treatment options. Ann Otol Rhinol Laryngol. 1993 Apr;102(4 Pt 1):303-8.
5. Maheut H, Arav E, Leone J, Lacour F, Toubas O, Pennaforte JL. Manifestations rénales de la maladie de Kimura: à propos d'un cas. Nephrologie. 1998;19(6):335-40.

6. Marcoux C, Bourlond A, Decroix J. Hyperplasie angiolymphoïde avec éosinophilie; Rémission sous acitrétine. Ann

Dermatol Venereol. 1991;118(3):217-21.

7. Chen H, Thompson LD. Kimura disease: a clinicopathologic study of 21 cases. Am J Surg Pathol. 2004 Apr;28(4):505-13.

8. Wells GC, Whimster IW. Subcutaneous angiolymphoid hyperplasia with eosinophilia. Br J Dermatol. 1969 Jan;81(1):1-14.

9. Ray V, Boisseau-Garsaud AM, Hillion G. Maladie de Kimura à localisation palatine chez un Antillais. Revue de médecine interne. 2003;24(4):253-256.

10. Dubert L. Thérapeutique dermatologique, Médecine-Sciences. Flammarion; 2001. Kimura et hyperplasie angiolymphoïde avec éosinophilie.

11. Laroche C, Bletry O. Février. 2005. La maladie de kimura. Encéclopédie Orphanet.

12. Shetty AK, Beaty MW, McGuirt WF, Jr, Woods CR, Givner LB. Kimura's disease: a diagnostic challenge. Pediatrics. 2002 Sep;110(3):e39.

13. Chen H, Thompson LD. Kimura disease: a clinicopathologic study of 21 cases. Am J Surg Pathol. 2004 Apr;28(4):505-13.

14. Som P, Biller H. Kimura's disease involving parotid gland and cervical lymph nodes: CT and MR findings. J Comput Assist Tomogr. 1992 MarApr;16(2):320-2.

15. Kawada A. Morbus Kimura: Darstellung der Erkrankung und ihre Differnential diagnose. Hautarzt. 1976 Jul;27(7):309-17. 